\title{
A SIMPLE MODIFICATION IN SNAIL ROTATION FLAP USED FOR SCALP RECONSTRUCTION
}

\author{
Usama Abd El Raouf Dakrory* and Tamer Mohsen Foad**
}

\begin{abstract}
The scalp is different, unlike any other site in the head and neck, it has the thickest skin in the human body and covers bone that protects the intracranial structures. Due to the special nature of scalp tissue, the reconstruction of defects is a challenging task. Many techniques have been used in scalp reconstruction from a simple approximation of the two edges of the scalp lesion, rotation flaps with their techniques as triple rotation, double-opposing rotation, pinwheel flaps up to utilization of regional flaps and tissue expanders. This study aims to introduce a small alteration in both the design and closure technique of the snail rotation flap used in scalp reconstruction to allow less rotation and easier approximation of the flap. This modified flap was used to manage seven cases three females and four males with scalp defects presented to the Oral and Maxillofacial Surgery Department, College of Oral and Dental Surgery, Misr University for Science and Technology and Dermatology, Venereology, and Andrology unit in the Memorial Souad Kafafi University Hospital, Misr University for Science and Technology. Results: Healing was optimum for all the patients except for one case who showed minimum dehiscence, hair shaft orientation was not markedly affected. Conclusions: closure of scalp defects is a challenge to surgeons due to the nature of the scalp and its surrounding tissues. This simple modification can help in scalp reconstruction with minimum tension and accepted healing.
\end{abstract}

\section{INTRODUCTION}

Scalp is unique and is different from other sites in the head and neck, it has the thickest skin in the human body and covers bone that protects the intracranial structures. ${ }^{[1]}$ Topographically, scalp consists of two parts; a hair bearing zone represented by temporal, parietal and occipital and a non-hair frontal zone which contains occipito-frontalis muscle that is connected by the galea aponeurotica ${ }^{[2,3]}$ Scalp defects are mainly due to trauma, tumor resection surgery, radiotherapy induced necrosis, burns and infections. ${ }^{[4]}$ Due to the special nature of scalp tissue

\footnotetext{
* Assistant Professor, Oral and Maxillofacial Surgery, College of Oral and Dental Surgery, Misr University for Science and Technology., Cairo, Egypt

** Assistant Professor, Dermatology, Venereology and Andrology Faculty of Medicine, Misr University for Science \& Technology. Cairo, Egypt
} 
being inelastic, convex in shape, moreover, the paucity of the adjacent tissues and high adherence of its layers (three layers out of its five layers behave as one unit gliding over the pericranium of the skull), all these factors render reconstruction of scalp defects a challenging task. ${ }^{[5]}$

Tissues adjacent to scalp defect are important in selection of the suitable reconstructive technique regarding tissue pliability, bone involvement and adherence to surrounding tissue due to burn or scar ${ }^{[2]}$

Many techniques have been used in scalp reconstruction starting from a simple approximation of the two edges of the scalp lesion, rotation flaps with their techniques as triple rotation ${ }^{[1]}$, doubleopposing rotation ${ }^{[6]}$ pinwheel flaps ${ }^{[7]}$ up to utilization of regional flaps and tissue expanders. ${ }^{[8]}$ Optimum scalp reconstruction is achieved via preservation of acceptable cosmetics and tension-free closure that provides a durable coverage especially in cases of exposure of calvarium or skull implants..$^{[9]}$

The aim of this study is to introduce a small change in the design and closure technique of the snail flap presented by Christopoulos ${ }^{[10]}$ resulting in improvement in advancement travelling distance of the flap with less rotation leading to reduction on suture points and more stable and durable coverage.

\section{PATIENTS AND METHOD}

This modified flap technique was used in surgical reconstruction of seven patients, three females and four males with age ranging from 4768 years with scalp defectspresented to the Oral and Maxillofacial Surgery Department, College of Oral and Dental Surgery, Misr University for Science and Technology and Dermatology, Venereology, and Andrology unit in the Memorial Souad Kafafi
University Hospital, Misr University for Science and Technology during a period of nearly two years starting from June 2019 till April 2021.

\section{The idea of modification:}

Consider a "circle of the defect" with a diameter of $2 \mathrm{X} \mathrm{cm}$, that results from the surgical excision of a lesion or other causes. Addition of a lateral arm to that circle with a width of nearly $\mathrm{X} \mathrm{cm}$ at its widest part that extending to a point near to $270^{\circ}$ is the modification in design, Fig. (1).

After elevation of the lateral arm and the rest of the flap with arc that is about four to six times the diameter of circle of defect, approximation of the lateral arm to the inner part of the circle, which is the modification in closure regarding snail flap, was performed easily especially with the aid of minimum rotation of the whole flap, Fig. (2). The next step is to advance the flap, advancementis distributed along the whole arc of the flap, lateral and lower border (opposite to the arc) of the circle of defect. Suturing was performed at two sites with better tension distribution. Figs. $(2,3)$.

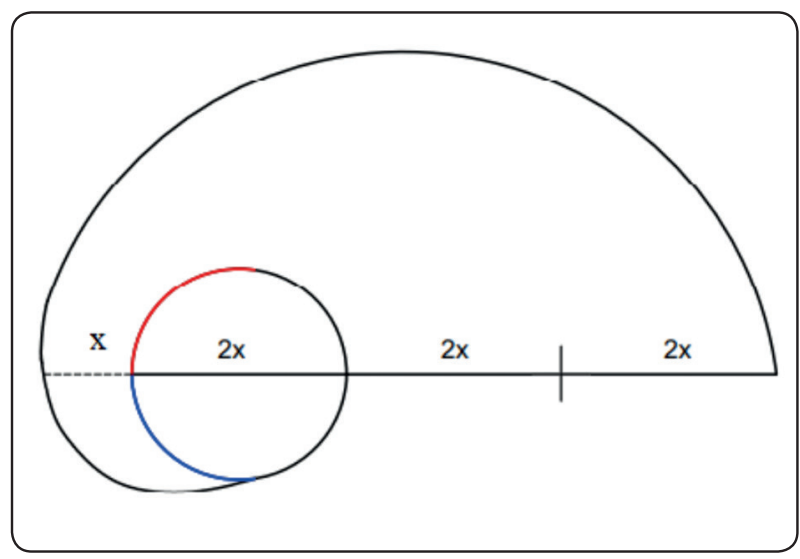

Fig. (1): Schematic diagram shows the modified design with a lateral extension with width of " $x$ " at widest part that meets the circle $\sim 270^{\circ}$. 


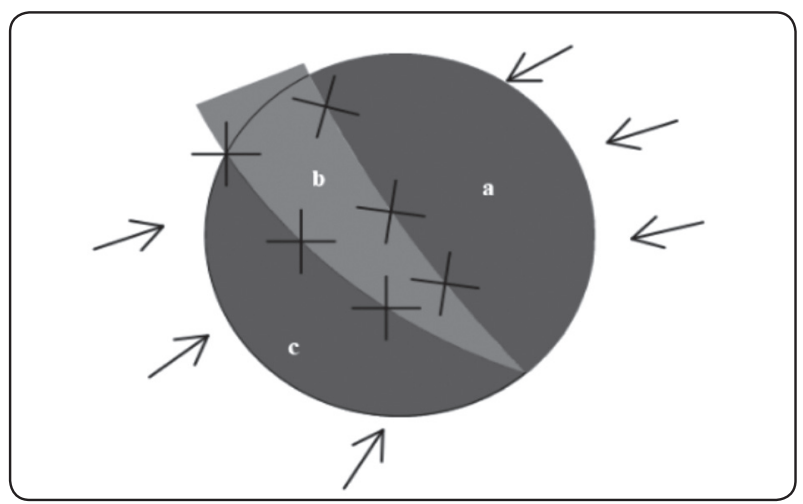

Fig. (2): Schematic diagram shows modification of closure regarding snail flap which used spiral closure. "a" represents the flap itself, " $b$ " is the modified part in the design, which is the lateral arm. While "c" represents the area lateral to the circle of defect, and it is normal unoperated part of the scalp. Arrows represent the horizontal advancement to allow closure at two sites represented by " $\mathrm{X}$ " marks.
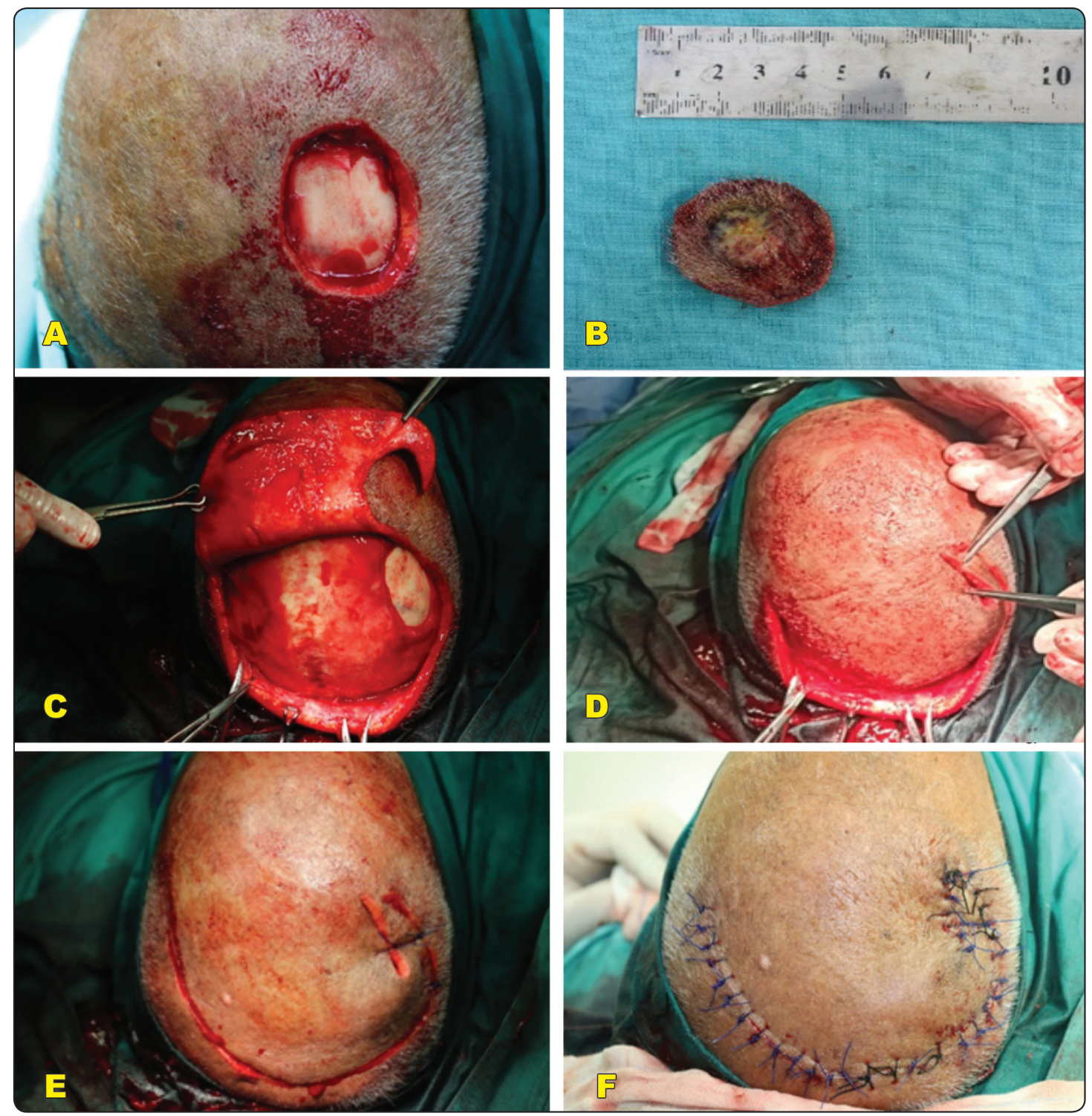

Fig. (3): Surgical steps of a case of basal cell carcinomain 68 years male, excision with closure with the modified flap. "a" and "b" show both surgical bed and the excised lesion. "c" represents the lateral arm that reaches $\sim 270^{\circ}$ which is the modification in design, while "d" represents themodification in closure technique regarding the snail flap. "e" shows that approximation of the lateral arm was performed in oblique manner without tension. "f" surgical closure with minimum rotation and accepted cosmetic. 


\section{RESULTS}

This study included seven patients, three females and four males with age ranging from 47-68 years with scalp defectsdue to different causes as shown in tables $(1,2)$.

TABLE (1): Patient distribution regarding gender and range of age.

\begin{tabular}{|l|c|c|}
\cline { 2 - 3 } \multicolumn{1}{c|}{} & Number of patients & Range of age \\
\hline Male & 4 & $50-68$ years \\
\hline Female & 3 & $47-62$ years \\
\hline
\end{tabular}

Intraoperatively, approximation of flap and tissues was performed easily with flap stability, minimal tension, and less flap rotation. Healing was followed up for 3 weeks post operatively, all the patients showed accepted healing except of one male case who showed minimum dehiscence that improved gradually with accepted healing (table 2). No infection or major dehiscence was reported. Generally, hair shaft orientation was not markedly affected, Fig. (4).

TABLE (2): Summarizes the cause of the surgical defects, defect diameter, and complications

\begin{tabular}{|c|c|c|c|}
\hline & Cause of the defect & Defect diameter range & Complications \\
\hline \multirow{2}{*}{ Male } & $\mathrm{BCC}(2$ cases $)$ & \multirow{2}{*}{$3-5 \mathrm{~cm}$} & $\begin{array}{l}\text { One case showed minimum dehiscence while the } \\
\text { other showed no dehiscence or morbidity }\end{array}$ \\
\hline & Infection ( 2 cases) & & No dehiscence or morbidity \\
\hline \multirow{2}{*}{ Females } & BCC ( 2 cases $)$ & \multirow{2}{*}{$4-5 \mathrm{~cm}$} & \multirow{2}{*}{ No dehiscence or morbidity } \\
\hline & $\mathrm{NHL}^{\$} \mathrm{~B}$ cell type & & \\
\hline
\end{tabular}

BCC*: Basal cell carcinoma NHL\$: non-Hodgkin lymphoma
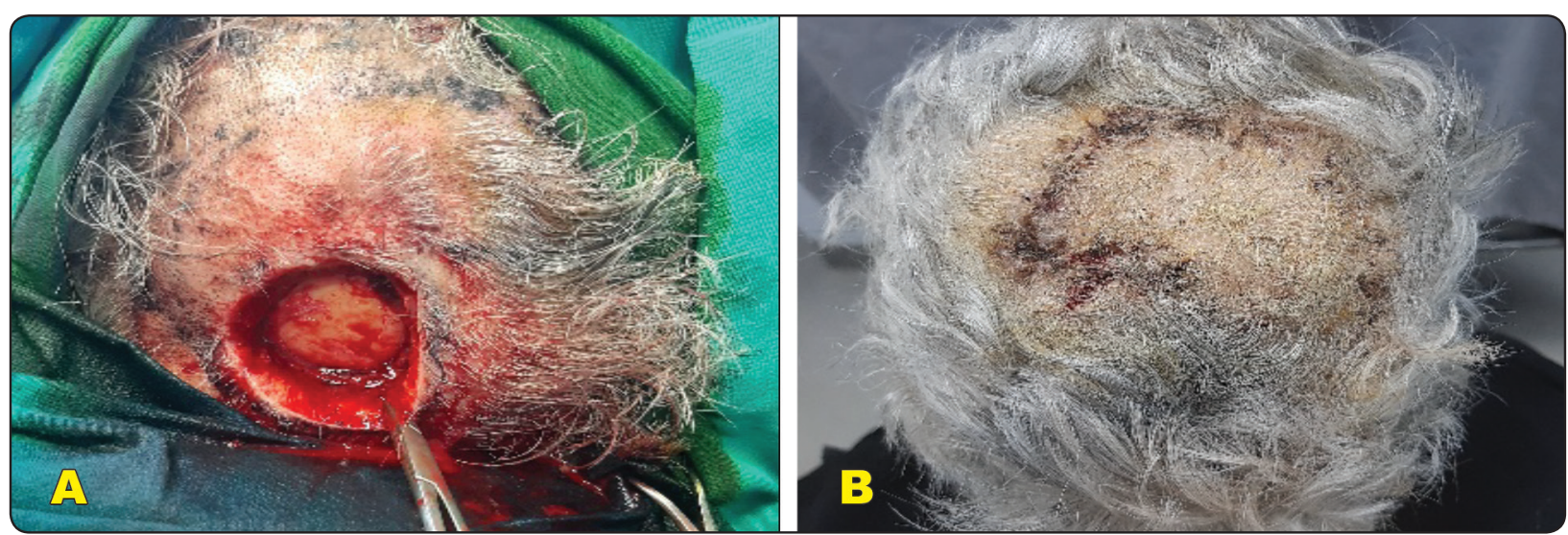

Fig. (4): a case with a surgical excision of non-Hodgkin lymphoma in 62 years female. "a" shows surgical bed after tumor excision, while "b" shows 3 weeks postoperative with accepted healing. 


\section{DISCUSSION}

Scalp reconstruction is a common surgical procedure to reconstruct scalp tissue defect resulted from tumor excision, trauma, radiotherapy induced necrosis, burn or even infection. ${ }^{[1]}$ Many reconstructive alternatives are available within the reconstructive ladder, the more local the better according to Gillies Principles of Plastic Surgery, principle no.9: 'Losses' (Loses must be replaced in kind) ${ }^{[12]}$ Based on commandment and ladder local flap should be addressed firstly if possible. When the defect is beyond the limitation of local flaps regarding size of defect and elasticity of tissue, regional flaps or free vascularized flaps will be the choice despite the prolonged operative time and postoperative complications. ${ }^{[3]}$

Rotation flap is a common flap used in scalp reconstruction with many different techniques. Despite simplicity in design, the nature of the scalp anatomy with tough inelastic aponeurosis over a concave vortex adds challenge to its usage. According to the remarkable work of Lo et $\mathrm{a}^{[13]}$ and as discussed by Manjunath ${ }^{[14]}$ triangulation of the flap is the basic concept during reconstruction flap design, but this study did not advocate that classical design and preferred the circle over triangle and the same did Paul. ${ }^{[15]}$ In case of tumor excision as an example, one $\mathrm{cm}$ as a safety margin is selected, in this case we get a "circle of defect" with a radius that is one $\mathrm{cm}$ longer than the radius of the lesion. Using simple geometry, it was found that the surface area of the circle of defectis only about $60 \%$ of the surface area of a triangle whose three arms are tangential to the circle ofdefect, Fig. (5).

This means that $40 \%$ of healthy tissue is saved, when it is recommended to use this type of flap. Same general rules of rotation flap were followed ${ }^{[16]}$, rotation within 30 degrees of an arc of circle, the diameter of the rotation circle is about 2-3 times the diameter of the defect and arc length is about four to six times of that diameter.

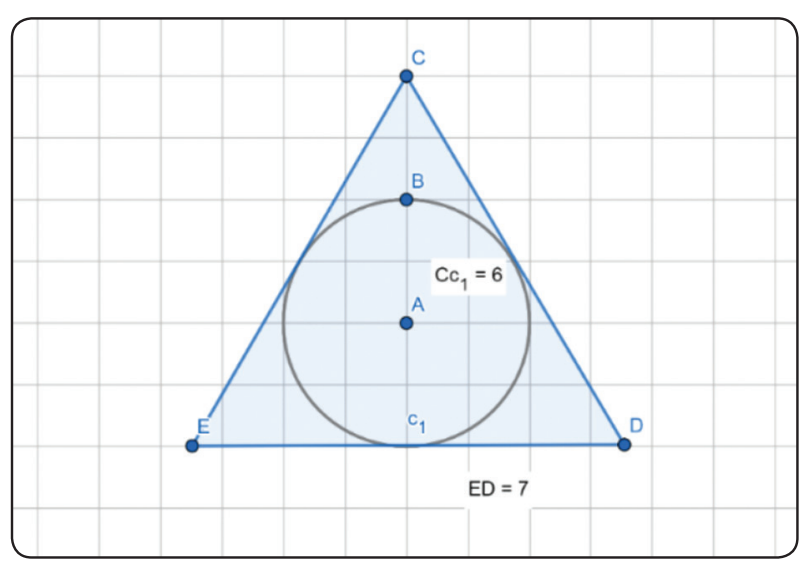

Fig. (5): Difference between surface area of a circle and its tangent triangle.

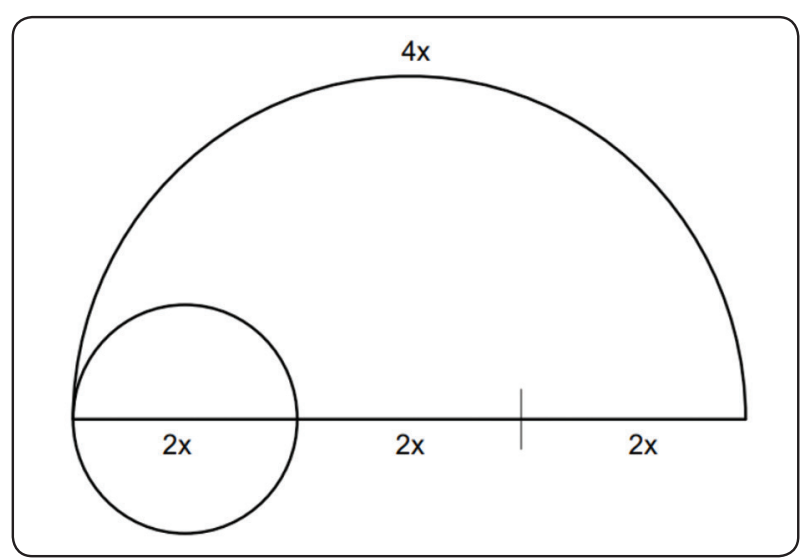

Fig (6): Schematic diagram of snail flap as presented by Christopoulos [10] (in case of elderly patients). Note that arm meet the circle nearly at $180^{\circ}$.

Modification offered in this study is represented by simple change in flap design and closure technique offered by Christopoulos ${ }^{[10]}$. Modification of the design is presented as a lateral extension of the arc with nearly the same width of the radius of the circle of defectat its widest part and meets nearly the $270^{\circ}$ point of circle of defect, as shown in Fig. (1) in contrast to the original snail where the end of the arc nearly meets the point of $180^{\circ}$, Fig. (6). This modified extension decreases the rotation of flap and allows tissue approximation to rely on horizontal advancement during closure, in contrast to the original snail rotation flap the used spiral closure with more rotation that subjects the flap to more tension. ${ }^{[15]}$ 
Beingoblique, this distributes the tension on sutures as closure occurs at three areas namely, the arc itself, the lateral border and finally the lower part of the flap (opposite to the arc). In other words, the flap needs to be advanced mainly in a horizontal direction rather than full rotation as presented in conventional rotation flap or the snail flap.

Due to the width of the extended arm, undermining of the whole surrounding tissue and performing scoring parallel to blood vessels in the layer of galea aponeurotica which was also performed by Manjunath $^{[14]}$, compensation of the defect can be done without tension.

On contrary to Christopoulos ${ }^{[10]}$ in his great article, closure technique of the flap parts was simpler without performing a spiral pattern or the snail closure, simply the edges were approximated in oblique pattern with suturing distributed at three different areas, with less rotation of the whole flap and less tension for better stability and durability of the closure.

The resulted dog ear is left with no intervention, using of elastic bandage and pressure reduced its size till it became undetected during the healing period, which was also recommended by other authors. ${ }^{[4]}$

\section{CONCLUSIONS}

Gains from the presented modifications are important, including decrease in flap advancement travelling distance with less flap rotation, accepted healing and better cosmetic as hair shaft orientation is not markedly affected. In addition to, reduction of tension on suture points either at donor or recipient sites provides flap stability.

\section{ACKNOWLEDGEMENT}

I would like to thank the amazing Architect "Fyrouz Tarek" for her outstanding patience and sincere help in designing sketches in this article.

\section{REFERENCES}

1. Shilpa, K., Divya, G., Budamakuntla, L., Lakshmi, D., Scalp Defect Reconstruction with Triple Rotation Flap: A Case Report. J Cutanour Aesthet Surg, 2018. 11(1): p. 26-28.

2. Gupta, P. and S. Srivastava, Reconstruction of Scalp with Local Axial Flaps.Int J Otorhinolaryngol Head Neck Surg, 2020. Sep;6(9):p. 1692-1699.

3. Pukar MM, S.U., Mantro Rubal, Reconstruction of scalp defect by rotation flap. Int J Res Health Sci, Apr 2014.2(2), p.690-692.

4. Vishwanath, K., N. Shetty, and S. Roy, Use of Rotational Flap for Reconstruction of Scalp Avulsion Defect - A Case Report. Journal of Health and Allied Sciences NU, 2017. 07: p. 063-065

5. Lee, B., K. Bickel, and S. Levin, Microsurgical reconstruction of extensive scalp defects. J Reconstr Microsurg, 1999. 15(4): p. 255-62; discussion 263-4

6. Ransom, E.R. and A.A. Jacono, Double-opposing rotationadvancement flaps for closure of forehead defects. Arch Facial Plast Surg, 2012. 14(5): p. 342-5.

7. Field, L.M., The Scalp "Pinwheel" Flap. The American Journal of Cosmetic Surgery, 1984. 1(2): p. 38-40.

8. Desai, S.C., Sand, J.P., Sharon, J.D., Branham, G., Nussenbaum, B., Scalp reconstruction: an algorithmic approach and systematic review. JAMA Facial Plast Surg, 2015. 17(1): p. 56-66.

9. Ooi, A.S., Kanapathy, M., Ong, Y.S., Tan, K.C., Tan, B.K., Optimising Aesthetic Reconstruction of Scalp Soft Tissue by an Algorithm Based on Defect Size and Location. Ann Acad Med Singap, 2015. 44(11): p. 535-41.

10. Christopoulos, G., Deraje, V., Mbaidjol, Z., Kannan, R.Y. The "Snail Flap": A Rotation Flap in Scalp Reconstruction. Plastic and Reconstructive Surgery - Global Open, 2020.8(1).

11. Garcia del Campo, J.A.,García de Marcos, J.A., Pardo de Vera, J.L., García de Marcos, M.J., Local flap reconstruction of large scalp defects. Med Oral Patol Oral Cir Bucal, 2008. 13(10): p. E666-70.

12. Pandey, S., Chittoria, R.K., Mohapatra, D.P., Friji, M.T., Sivakumar, D.K., Mnemonics for gillies principles of plastic surgery and it importance in residency training programme. Indian J Plast Surg, 2017. 50(1): p. 114-115.

13. Lo, C.H. and F.W. Kimble, The ideal rotation flap: an experimental study. J Plast Reconstr Aesthet Surg, 2008. 61(7): p. 754-9. 
14. Manjunath, K., M. Venkatesh, and D. Vishwanath, Scalp Rotation Flap-Minor Changes Major Gains. Anaplastology, 2017.06.

15. Paul, S. and R. Norman, Clinical Cases in Skin Cancer Surgery and Treatment Series: Clinical Cases in Dermatol- ogy. 2015 p.31-43, Springer International Publishing AG, Switzerland.

16. Patel, K. and J. Sykes, Concepts in local flap design and classification. Operative Techniques in Otolaryngologyhead and Neck Surgery, 2011. 22: p. 13-23. 